\title{
A QUALIFICAÇÃO PROFISSIONAL COMO POSSIBILIDADE DE RESSOCIALIZAÇÃO DOS JOVENS EM CUMPRIMENTO DE MEDIDAS SOCIOEDUCATIVAS
}

\begin{abstract}
THE PROFESSIONAL QUALIFICATION AS A POSSIBILITY OF RESOCIALIZATION OF YOUTH IN FULFILLMENT OF SOCIO-EDUCATIONAL MEASURES
\end{abstract}

\section{RESUMO}

\author{
Stephanie Freires Bastos ${ }^{1}$ \\ Mario Lopes Amorim²
}

Este artigo tem por objetivo contribuir para a discussão de medidas político-pedagógicas direcionadas a jovens considerados infratores, as quais têm por finalidade assegurar ao jovem o direito à inserção no mundo do trabalho por meio da educação voltada à profissionalização qualificada. Para reforçar as diretrizes do ECA, bem como ampliar a aplicabilidade das medidas socioeducativas para jovens infratores, foi sancionada a Lei ${ }^{\circ} 12.594$, de 12 de janeiro de 2012, que institui o SINASE, criado com a finalidade de regulamentar a execução de medidas pedagógicas destinadas a adolescentes praticantes de atos infracionais inimputáveis. Trata-se de uma revisão bibliográfica, considerando a relação entre qualificação profissional e ressocialização a partir do referencial metodológico do materialismo histórico dialético, o qual possibilita a aproximação não só da aparência dos fenômenos, mas também da essência da realidade, neste caso vinculado à compreensão da aplicação das medidas socioeducativas relacionados à qualificação para o mundo do trabalho dos jovens infratores. Ao jovem em cumprimento de medida socioeducativa, todas as ações devem ter como objetivo interferir de maneira positiva e não apenas de forma punitiva, no processo de desenvolvimento educativo, mas também buscando a sua integração social.

Palavras-chave: Medidas Socioeducativas. Mundo do trabalho. Qualificação Profissional. Ressocialização.

\begin{abstract}
This article aims to contribute to the discussion of political-pedagogical measures directed at teenagers considered offenders, which aim to ensure the teenager the right become inserted in the world of work through education aimed at professionalization qualified. To strengthen the ECA guidelines, as well as expand the applicability of educational measures for young offenders, was sanctioned the law number 12.594, of January 12th, 2012, establishing the SINASE, created with the purpose of regulating the implementation of measures aimed at teaching teenagers practicing unimputable infractional deeds. This is a literature review, considering the relationship between professional training and re-socialization from the methodological referential of the historical dialectic materialism, which makes the approach not only the appearance of phenomena, but also

\footnotetext{
${ }^{1}$ Mestranda do Programa de Pós-Graduação em Tecnologia e Sociedade da Universidade Tecnológica Federal do Paraná (UTFPR). fany_bastos@hotmail.com.

${ }^{2}$ Docente do Programa de Pós-Graduação em Tecnologia e Sociedade da Universidade Tecnológica Federal do Paraná (UTFPR).marioamorim@utfpr.edu.br.
} 
the essence of reality, in this case linked to the understanding of socio-educational measures related to qualification for the world of work of young offenders. The teenagers in fulfillment of socioeducational measure, all actions must aim to interfere in a positive way and not just punitive way, in the process of developing educational, but also seeking your social integration.

Keywords: Socio-educational Measures. World of Work. Professional Qualification. Resocialization.

\section{INTRODUÇÃ̃O}

$\mathrm{O}$ aumento dos índices de adolescentes que integram o sistema socioeducativo brasileiro indica que, apesar de todo aporte legal, muito pouco se faz no processo de ressocialização desses adolescentes na sociedade, fato percebido quando se observa o índice de reincidência dos atos infracionais. As medidas socioeducativas buscam agir de maneira positiva sobre a formação do adolescente, porém a educação e o trabalho são as formas mais transformadoras de si próprias e do meio onde se está inserido. Neste sentido, o presente artigo propõe analisar a relação entre educação, trabalho e ressocialização, levando em consideração o conceito de trabalho em sua dimensão ontológica, ou seja, aquela que considera o trabalho como processo coletivo no qual o ser social produz as condições gerais da existência humana, sendo fonte de produção, conhecimentos e saberes, portanto princípio educativo. O referencial teórico-metodológico que será utilizado como base para discussão das categorias será o materialismo histórico e dialético, que segundo Triviños (1987, p. 128), “intenta captar não só a aparência do fenômeno, como também sua essência", pois compreende todo o contexto, neste caso vinculado ao cumprimento da medida socioeducativa, influenciada pela escolarização e determinada pela oportunidade do trabalho.

$\mathrm{O}$ artigo inicialmente realiza um breve histórico sobre a legislação da socioeducação e seus indicadores no Brasil. A seguir, apresenta o conceito do trabalho como princípio educativo apoiado em Kuenzer (1989), mostrando as premissas gramscianas da consciência que o trabalhador tinha sobre a apropriação do conhecimento produzido socialmente na escola frente à fragmentação da aplicação prática no seu cotidiano profissional, bem como da dualidade estrutural encontrada na modalidade da qualificação profissional, a qual foi construída hegemonicamente por um sistema capitalista desigual. Por fim, considera que educar para o convívio social é também educar o adolescente jovem infrator para o exercício da cidadania, dando condições necessárias para a inserção ao mundo do trabalho, de forma crítica e autônoma. 
Por se tratar de um artigo baseado em uma dissertação, que ainda está no início, o artigo não apresentará resultados ou hipóteses, apenas uma conclusão sobre o panorama encontrado a partir do referencial teórico.

\section{CONTEXTO LEGAL}

Segundo Costa (2004), as medidas socioeducativas visam educar o adolescente para o convívio social, por isso o nome socioeducativo. Educar para o convívio social é educar o jovem para o exercício da cidadania, ou seja, a medida socioeducativa possui relação direta com a função da escola. Ao jovem em cumprimento de medida socioeducativa, todas as ações têm como objetivo interferir de maneira positiva e não apenas punindo, no processo de desenvolvimento, buscando então a integração social.

A garantia de direitos dos jovens em atendimento socioeducativo é apresentada desde a Constituição Federal de 1988, nos incisos IV e V, do parágrafo $3^{\circ}$, do artigo 227 , que trata do direito a proteção especial de adolescentes. Com a Lei Federal 8.069, de 13 de julho de 1990, que cria o Estatuto da Criança e do Adolescente - ECA, e estabelece à doutrina da proteção integral, as medidas socioeducativas passaram a ser articuladas com o conjunto de políticas setoriais direcionadas aos adolescentes da socioeducação, além de estabelecer as políticas de atendimento e dispor sobre a apuração dos atos infracionais. Em seu artigo 112, capítulo IV, seção I, prevê que adolescentes que cometem ato infracional podem ser vinculados às medidas socioeducativas, com a aplicação das seguintes medidas:
a) advertência;
b) obrigação de reparar o dano;
c) prestação de serviços à comunidade;
d) liberdade assistida;
e) inserção em regime de semiliberdade;
f) internação em estabelecimento educacional;
g) qualquer uma das previstas no art. 101, I a VI.

Em 1996, o Conselho Nacional dos Direitos da Criança e do Adolescente CONANDA - aprovou as Resoluções $n^{\circ} 46$ e 47, que apresentam definições específicas sobre a 
internação e a semiliberdade, além de definir que essa medida deverá ser executada de forma que proporcione ao adolescente atividades educativas, de educação profissional e lazer durante o dia, acompanhado pela equipe especializada, e o convivo familiar no período noturno. Em 2004, o Ministério da Saúde institui a Política Nacional de Atenção Integral à Saúde de Adolescentes em Conflito com a Lei - PNAISARI, onde são apresentadas as diretrizes para implantação e implementação da atenção à saúde para essa população. Em 2005 foi publicada a Política Nacional de Assistência Social, pelo Ministério do Desenvolvimento Social e Combate à Fome, onde as medidas socioeducativas foram inseridas no escopo da atuação da política da assistência social.

Em 2006 o CONANDA, por meio da Resolução n 119/2006, cria o Sistema Nacional de Atendimento Socioeducativo - SINASE, reforçando a garantia dos direitos dos adolescentes da socioeducação e a natureza pedagógica da medida socioeducativa, "fruto de uma construção coletiva que envolveu diversas áreas do governo, representantes de entidades e especialistas na área, além de uma série de debates protagonizados por operadores do Sistema de Garantia de Direitos em encontros regionais que cobriram todo o país" (CONANDA, 2006, p. 12). Em 2009, através da Resolução ${ }^{\circ}$ 109, instituída pelo Conselho Nacional de Assistência Social, foram apresentados e regulamentados o Serviço de Proteção Social a Adolescentes em Cumprimento de Medidas Socioeducativas de Liberdade Assistida e de Prestação de Serviço à Comunidade, onde são descritos objetivos, seguranças, tipificação dos serviços, possibilitando a padronização deste serviço. Neste contexto, em 2012, foi promulgada a Lei $\mathrm{n}^{\circ} 12.594$ que institui o SINASE, com o objetivo de regulamentar a execução das medidas socioeducativas, unificando os procedimentos de aplicação e monitoramento das medidas socioeducativas pelo Sistema de Justiça, bem como atribuindo a este sistema um novo papel de acompanhamento das medidas socioeducativas. No mesmo ano, o Conselho Nacional de Educação publicou a Resolução CNE/CP n ${ }^{\circ}$ 1, onde foram estabelecidas as Diretrizes Nacionais para a Educação em Direitos Humanos. Em 2013, o Ministério da Educação emitiu a Nota Técnica $n^{\circ} 38$, orientando as Secretarias Estaduais de Educação para a implementação da Lei do SINASE. No mesmo ano o CONANDA publicou a Resolução $n^{\circ}$ 160, aprovando o Plano Nacional de Atendimento Socioeducativo, que prevê ações articuladas, no horizonte de 10 anos, nas áreas da educação, saúde, assistência social, cultura, educação profissional e esporte, além de apresentar o modelo de gestão do atendimento socioeducativo. 
Apesar de todo o embasamento legal instituído nacionalmente, segundo o Levantamento Anual da SINASE, no Brasil o número de adolescentes e jovens em cumprimento de medida socioeducativa cresceu 12\% de 2012 (20.532 adolescentes e jovens) a 2013 (23.066 adolescentes e jovens). No Paraná, o aumento foi de 7\% de 2012 (933 adolescentes e jovens) a 2013 (999 adolescentes e jovens). Estes índices reforçam a necessidade da revisão dos métodos de atendimento aos adolescentes da socioeducação. Segundo o SINASE:

O adolescente deve ser alvo de um conjunto de ações socioeducativas que contribua na sua formação, de modo que venha a ser um cidadão autônomo e solidário, capaz de se relacionar melhor consigo mesmo, com os outros e com tudo o que integra a sua circunstância e sem reincidir na prática de atos infracionais. Ele deve desenvolver a capacidade de tomar decisões fundamentadas, com critérios para avaliar situações relacionadas ao interesse próprio e ao bem comum, aprendendo com a experiência acumulada individual e social, potencializando sua competência pessoal, relacional, cognitiva e produtiva. (NUNES; BOSCO, 2016).

Neste contexto, a ideia de oportunizar ao jovem infrator a qualificação profissional faz sentido quando se compreende a relação indissociável entre trabalho, ciência, tecnologia e cultura. Compreende-se o trabalho como princípio educativo, como a primeira mediação entre o homem e a realidade capitalista em que está inserido. Segundo o Documento Base da Educação Profissional Técnica de Nível Médio Integrada ao Ensino Médio (2007),

formar profissionalmente não é preparar exclusivamente para o exercício do trabalho, mas é proporcionar a compreensão das dinâmicas socioprodutivas das sociedades modernas, com suas conquistas e os seus revezes, e também habilitar as pessoas para o exercício autônomo e crítico de profissões, sem nunca se esgotar a elas.

(BRASIL. MEC. SETEC, 2007, p. 45)

\section{O TRABALHO COMO PRINCÍPIO EDUCATIVO}

Desde as sociedades mais primitivas a educação coincidia com o processo de trabalho do homem, ou seja, "os homens apropriavam-se coletivamente dos meios de produção da existência e durante esse processo educavam-se e educavam as novas gerações” (SAVIANI, 1994, p. 152). Com a apropriação da terra, o principal meio de produção até então, duas classes sociais fundamentais foram criadas, que estão intimamente ligadas à organização do trabalho, são elas: a classe dos proprietários, donos de terra; e a dos não proprietários, aqueles que passaram a ter obrigação com o seu trabalho de manter a si mesmos e aos donos de terras. Na Antiguidade, tanto grega como romana, onde existia a aristocracia e os escravos, o que caracterizou o modo de 
produção escravista foi o trabalho ser realizado predominante pelos escravos. Essa diferenciação das classes também afetou a educação, que a partir do escravismo divide-se em duas classes: uma proprietária, ou seja, a educação para os homens livres, centradas nas atividades intelectuais, na arte da palavra e nos exercícios físicos de caráter lúdico ou militar; e outra não-proprietária, ou seja, a educação dos escravos, essa sim direcionada ao processo de trabalho. A primeira classe de educação, a classe proprietária, deu origem à escola, inicialmente um lugar do ócio, desenvolvendo a partir daí uma forma específica de educação, aquela em contraposição ao processo produtivo. Esse novo tipo de educação identificou-se como educação propriamente dita, criando então a separação entre educação e trabalho. A partir deste momento iniciou-se o processo de institucionalização da educação, concomitante com o surgimento de classes, que aprofundou ainda mais a divisão do trabalho.

Diante do entendimento da escola como um aparelho ideológico do Estado, a sociedade de classes contribuiu para a consolidação da separação entre trabalho e educação. Essa separação reflete que a divisão foi se processando em trabalho manual e trabalho intelectual. Analisando-se por esse ângulo, percebe-se que a separação entre escola e produção não condiz com a separação entre educação e trabalho. "De um lado, no trabalho manual, a educação se realiza concomitantemente com o próprio trabalho" (Saviani, 1994, p. 155), mesmo os trabalhos que exigiam alto grau de especialização eram exercidos juntamente com os "mestres de ofícios"; de outro, a educação para o trabalho intelectual era do tipo escolar, focada na preparação dos futuros dirigentes. Na sociedade feudal, como se sabe, produzia-se para o próprio consumo; baseada em uma economia de subsistência, quando restava algo da produção própria era possível o sistema de troca, que aumentou com a economia medieval ativando o comércio e organizando o processo de produção especificamente para a troca, dando origem à sociedade capitalista. Nesta sociedade, o eixo da produção desloca-se do campo para a cidade. Com o aumento da indústria, os ofícios foram simplificados, reduzindo a necessidade de qualificação específica, que foi viabilizada pela máquina. Neste processo pode-se perceber uma nova relação da educação com o trabalho, com o caráter abstrato do trabalho e o caráter abstrato próprio das atividades intelectuais, ou seja, a máquina viabilizou a materialização das funções intelectuais no processo produtivo, tornando a escola à via para essa objetivação.

Nos estudos de Acácia Kuenzer (1989) sobre como superar o academicismo rançoso e o profissionalismo estreito, uma das primeiras premissas levantadas foi à consciência que o 
trabalhador tinha sobre a apropriação do conhecimento produzido socialmente na escola frente à fragmentação da aplicação prática no seu cotidiano profissional. Já em sua segunda pesquisa, realizada em 1988, a autora verificou que, apesar da má qualidade da educação de $2^{\circ}$ grau, os trabalhadores acreditavam que seria através dessa educação que teriam a possibilidade de ingressar no mercado de trabalho e, possivelmente, um futuro na educação superior. Segundo Kuenzer (1989, p. 22):

[...] em ambas as pesquisas, fica evidente que a classe trabalhadora reivindica o acesso a um saber que lhe permita, ao mesmo tempo, participar ativamente do processo político e do sistema produtivo, enquanto compreende as relações sociais que determinam seu modo de vida, sua concepção de mundo e sua consciência.

Kuenzer considera que o problema da educação é político, uma vez que a divisão entre conhecimentos intelectuais e manuais, na prática, não existe, porque todo trabalho instrumental tem uma dimensão intelectual e vice-versa. Tomando o trabalho como princípio educativo, é possível desenvolver uma educação que reunifique cultura e produção, considerando um ensino que será único, politécnico, teórico-prático, democrático e moderno e atualizado. Gramsci define que o trabalho como princípio educativo é um pressuposto ontológico e ético político no processo de socialização humana. Segundo Gramsci, as mudanças tecnológicas não alteraram apenas a organização do trabalho, mas também toda a relação do sistema capitalista com a sociedade. Com isso, é necessária uma nova proposta de escola que, além de preservar a essência humanística tradicional, considere a técnica da escola profissional que desenvolve a capacidade do trabalho manual, próprio da indústria moderna. Nesse sentido, pressupõe a formação total do homem, "na supressão da divisão do trabalho entre os homens, a educação, instrução, preparação de homens omnilateralmente desenvolvidos e omnilateralmente preparados, de homens capazes de fazer tudo" (MANACORDA, 1990, p. 99), educando-os para a liberdade. Essa concepção educativa, dialética e materialista, pressupõe a historicidade que recria a natureza das necessidades produzidas, transformando a realidade.

\section{QUALIFICAÇÃO PROFISSIONAL COMO MEIO DE RESSOCIALIZAÇÃO}

O trabalho, quando entendido como princípio educativo, diferente do trabalho enquanto entrega de mão-de-obra, tem como referência o desenvolvimento pessoal para o exercício da cidadania, integrado ao desenvolvimento profissional que possibilite a compreensão e a atuação 
no mundo, para que haja a reinserção social, criando então uma possibilidade concreta de mudança de contexto social. Partindo deste princípio do trabalho como organizador dos conteúdos a serem desenvolvidos, será possível democratizar o saber científico e tecnológico, que permitirá ao adolescente a participação ativa na vida social, política e produtiva.

Neste sentido, a qualificação profissional pode ser entendida como meio de ressocialização dos adolescentes da socioeducação, porque, conforme as perspectivas de Pierre Naville, a qualificação deve ser compreendida como parte de um processo de construção social dos indivíduos, não somente considerando o âmbito laboral, mas sim integrando a aquisição das capacidades, os modos de vida e as situações de trabalho (FERRETTI, 2004). Neste sentido, conforme Ferretti compreende-se a qualificação como um fenômeno que considera os aspectos sociais, culturais, políticos e econômicos, que são influenciados pelo tempo e espaço, e não apenas como resultado do processo de aprendizagem dos conteúdos do trabalho. Neste cenário, a qualificação profissional entendida como meio de ressocialização dos adolescentes da socioeducação tem como base, conforme proposta por Kuenzer:

\footnotetext{
A aquisição dos princípios teórico-metodológicos básicos que estão na base da ciência e da tecnologia contemporâneas; a apropriação de conteúdos histórico-críticos, que permitam a compreensão das relações sociais em seu conjunto; o domínio de algumas formas tecnológicas que permitam o exercício de funções produtivas; o domínio dos códigos e das formas correntes de comunicação. (KUENZER, 1989, p. 25)
}

\section{CONCLUSÃO}

Na busca da compreensão sobre o trabalho surgem várias questões relacionadas à divisão do trabalho e a divisão de classes; sobre o papel da propriedade privada na diferenciação do trabalho e da educação; sobre a educação que atende ao capitalismo e a educação politécnica. A nova pedagogia da hegemonia do capital busca naturalizar o ideário da globalização e de inserção subalterna na divisão internacional do trabalho, que opta pela cópia da tecnologia e a consequente supremacia do investimento na reprodução do trabalho simples; é uma escolha interna do modo como à classe dominante brasileira se alimenta e produz a sociedade que somos. O significado político, econômico, social e cultural desse modo de pensar não só inviabiliza a construção de um projeto nacional autônomo como também traz enormes danos à sociedade, como o aumento dos índices da socioeducação. Conforme expresso por COSTA (2004, p. 26), 
A ausência de alternativas concretas, que lhe permitam viabilizar-se como pessoa, trabalhador e cidadão, acabam levando o adolescente a murar-se no imediatismo, esse insaciável devorador de horizontes, e na inconsequência, a sua irmã siamesa. A partir daí, torna-se cada vez mais difícil o trabalho social e educativo com esses jovens. Agora, já não é a simples reposição do que lhes foi sonegado que os levará ao caminho do normal crescimento de uma vida e de uma carreira. Aqui, a existência já está comprometida em níveis mais profundos.

A tarefa de transformação da realidade dos adolescentes da socioeducação idealizada, por alguns, é muito diferente da realidade que se encontra a socioeducação brasileira hoje. Além das mudanças que a educação brasileira vem sofrendo, a atual reformulação do ensino médio, vendida pelo governo como instrumento para a melhoria da educação no país, propõe a flexibilização da grade curricular baseada na Base Nacional Comum, excluindo cada vez mais os adolescentes da socioeducação. Com este cenário, é urgente analisar novas estratégias de enfrentamento do problema. Esse artigo tentou propor uma nova possibilidade de transformação do contexto dos adolescentes da socioeducação. A vulnerabilidade em que esses adolescentes se encontram, resultado muitas vezes da evasão e/ou defasagem escolar, do contexto familiar inexistente ou frágil, leva-os a ingressar no mercado de trabalho precário e sem perspectivas. A partir deste artigo entende-se que, quando é proporcionada a oportunidade de colocação no mercado do trabalho, com acompanhamento e supervisão, juntamente com a qualificação profissional com foco em desenvolvimento integral do cidadão e na continuidade dos estudos na escolarização básica, o jovem infrator poderá ter uma oportunidade de ressocialização, principalmente quando o trabalho é entendido e tratado como princípio educativo, proporcionando novas experiências e entendimentos desses jovens e da sociedade como um todo.

\section{REFERÊNCIAS}

BRASIL. Constituição (1988). Disponível em:

〈http://www.planalto.gov.br/ccivil_03/constituicao/constituicaocompilado.htm〉. Acesso em: 27 jul. 2018.

BRASIL. Lei n. 8.069, de 13 de julho de 1990. Dispõe sobre o Estatuto da Criança e do Adolescente e dá outas providências. Diário Oficial da União República Federativa do Brasil, Brasília, DF, 16 jul. 1990. Disponível em: $<$ http://www.planalto.gov.br/ccivil_03/leis/L8069.htm>. Acesso em: 27 jul. 2018.

BRASIL. Lei n. 12.594, de 18 de janeiro de 2012. Institui o Sistema Nacional de Atendimento Socioeducativo (SINASE), regulamenta a execução das medidas socioeducativas destinadas a 
adolescente que pratique ato infracional. Diário Oficial da União República Federativa do Brasil, Brasília, DF, 19 jan. 2012. Disponível em: < http://www.planalto.gov.br/ccivil_03/_ato2011-2014/2012/lei/112594.htm>. Acesso em: 27 jul. 2018.

BRASIL. MDS. CNAS. Resolução n ${ }^{\circ}$ 109, de 11 de novembro de 2009. Aprova a Tipificação Nacional de Serviços Socioassistenciais. Diário Oficial da União República Federativa do Brasil, Brasília, DF, 25 nov. 2009. Disponível em: < http://www.mds.gov.br/webarquivos/legislacao/assistencia_social/resolucoes/2009/Resolucao\%2 0CNAS\%20no\%20109-\%20de\%2011\%20de\%20novembro\%20de\%202009.pdf>. Acesso em: 27 jul. 2018.

BRASIL. MEC. CNE/CP. Resolução no 1, de 30 de maio de 2012. Estabelece Diretrizes Nacionais para a Educação em Direitos Humanos. Disponível em: < http://portal.mec.gov.br/dmdocuments/rcp001_12.pdf>. Acesso em: 27 jul. 2018.

BRASIL. MEC. SECADI. DPEDHUC. CGDH. Nota Técnica no 38/2013. Orientação às Secretarias Estaduais de Educação para a implementação da Lei $n^{\circ} 12.594$, de 18 de janeiro de 2012, que institui o Sistema Nacional de Atendimento Socioeducativo (Sinase). Disponível em: < http://ens.sinase.sdh.gov.br/ens2/images/conteudo/nota\%20te\%CC\%81cnica\%2038\%20_\%20sin ase.pdf $>$. Acesso em: 27 jul. 2018.

BRASIL. MEC. SETEC. Educação profissional técnica de nível médio integrado ao ensino médio, Documento Base. Brasília, MEC, 2007.

BRASIL. PRESIDÊNCIA DA REPÚBLICA. SDH. Resolução CONANDA n 46, de 29 de outubro de 1996. Regulamenta a execução da medida sócio-educativa de internação prevista no Estatuto da Criança e do Adolescente, Lei no 8.069/90. Disponível em: < https://www.legisweb.com.br/legislacao/?id=95825 >. Acesso em: 27 jul. 2018.

BRASIL. PRESIDÊNCIA DA REPÚBLICA. SDH. Resolução CONANDA n 47, de 06 de dezembro de 1996. Regulamenta a execução da medida sócio-educativa de semiliberdade, a que se refere o art. 120 do Estatuto da Criança e do Adolescente, Lei nº 8069/90. Disponível em: < https://www.angra.rj.gov.br/downloads/SAS/sinase/resolucao_conanda_n47_1996.pdf>. Acesso em: 27 jul. 2018.

BRASIL. PRESIDÊNCIA DA REPÚBLICA. SDH. Resolução CONANDA n 160, de 18 de novembro de 2013. Aprova o Plano Nacional de Atendimento Socioeducativo. Disponível em: < http://dh.sdh.gov.br/download/resolucoes-conanda/res-160.pdf>. Acesso em: 27 jul. 2018.

BRASIL. Secretaria de Direitos Humanos. Levantamento Anual SINASE 2013: Privação e Restrição de Liberdade, Brasília: SDH, 2015.

BRASIL. Secretaria Especial dos Direitos Humanos. Sistema Nacional de Atendimento Socioeducativo - SINASE. Brasília: CONANDA, 2006. 
COSTA, A. C. G. Por uma política nacional de execução das Medidas Socioeducativas: conceitos e princípios norteadores. Brasília: Secretaria Especial de Direitos Humanos, 2004.

FERRETTI, C. J. Considerações sobre a apropriação das noções de qualificação profissional pelos estudos a respeito das relações entre trabalho e educação. Revista Educação \& Sociedade, Campinas, v.25, n.87, mai/ago de 2004. Disponível em:<http://www.scielo.br/pdf/es/v25n87/21463.pdf>. Acesso em: 04 set. 2016.

KUENZER, A. O trabalho como princípio educativo. Caderno de Pesquisa. São Paulo (68): 21-28, 1989.

MANACORDA, M. A. O princípio educativo em Gramsci. Porto Alegre: Artes Médicas, 1990.

NUNES, M. C.; BOSCO, G. P. Sistema Nacional de Atendimento Socioeducativo (SINASE): Lei $n^{\circ} 12.594$, de 18 de janeiro de 2012. Revista Jus Navegandi, São Paulo, ago. 2016. Disponível em: $<$ https://jus.com.br/artigos/51212/sistema-nacional-de-atendimento-socioeducativo-sinase-lein-12-594-de-18-de-janeiro-de-2012>. Acesso em: 27 jul. 2018.

RAMOS, M. N. A pedagogia das competências: autonomia ou adaptação? São Paulo: Editora Cortez, 2001.

SAVIANI, Dermeval. O trabalho como princípio educativo frente às novas tecnologias. In: FERRETTI, Celso J. et al. (Orgs.). Novas tecnologias, trabalho e educação: um debate multidisciplinar. Petrópolis: Vozes, 1994.

TARTUCE, G. L. B. P. Tensões e Intenções na Transição Escola-Trabalho: um estudo das vivências e percepções de jovens sobre os processos de qualificação profissional e (re)inserção no mercado de trabalho na cidade de São Paulo. São Paulo: Universidade de São Paulo, 2007.

TRIVIÑOS, A. N. S. Introdução à pesquisa em ciências sociais: a pesquisa qualitativa em educação: o positivismo, a fenomenologia, o marxismo. São Paulo: Atlas, 1987. 